\title{
Clinical phenotype clustering in cardiovascular risk patients for the identification of responsive metabotypes after red wine polyphenol intake
}

Rosa Vázquez-Fresno ${ }^{1}$, Rafael Llorach ${ }^{1 *}$, Alexandre Perera $^{2}$, Rupasri Mandal $^{3}$, Francisco J

Tinahones $^{4}$, David S Wishart ${ }^{3}$, Cristina Andrés-Lacueva ${ }^{1^{*}}$

${ }^{1}$ Biomarkers \& Nutrimetabolomic Lab, Nutrition and Food Science Department, XaRTA, INSA,

Campus Torribera, Pharmacy Faculty, University of Barcelona, Barcelona 08028, Spain.

INGENIO-CONSOLIDER Programme, Fun-C-Food CSD2007-063, Ministry of Science and

Innovation, Barcelona, Spain. ${ }^{2}$ Dept. ESAII, Technical University of Catalonia (UPC),

Barcelona, Spain. Biomedical Engineering Research Center (CREB), Barcelona, Spain.

CIBER-BBN in Bioengineering, Biomaterials and Nanomedicine, Spain. ${ }^{3}$ Department of

Computing Science \& Department of Biological Sciences, Faculty of Science, University of

Alberta, Edmonton, AB, Canada T6G 2E9. ${ }^{4}$ Fundación IMABIS, and Servicio de

Endocrinología y Nutrición, Hospital Universitario Virgen de la Victoria, Spain. CIBER

Fisiopatología de la Obesidad y Nutrición (06/03), Instituto de Salud Carlos III, Málaga, Spain

*Corresponding authors: Dr. Cristina Andrés-Lacueva (e-mail: candres@ub.edu) and Dr.

Rafael Llorach, (e-mail: rafallorach@ub.edu). Biomarkers \& Nutrimetabolomic Lab, Nutrition and Food Science Department, XaRTA, INSA, Campus Torribera, Pharmacy Faculty,

University of Barcelona, Barcelona 08028, Spain

KEYWORD: metabolic phenotype, metabolomics, metabotype, cardiovascular disease, wine polyphenols, NMR, 4-hydroxyphenylacetate, gut microbiota 


\section{ABSTRACT}

Metabolic phenotypes of individuals are the result of genes, environment, lifestyle, diet and gut microbiota interactions. The aim of this study is to evaluate the robustness of clinical and metabolic phenotyping in identifying differential responsiveness to dietary strategies in the improvement of cardiometabolic status. Clinical phenotyping of 57 male volunteers with high cardiovascular risk factors was performed using $K$-means cluster analysis based on 69 anthropometric and plasma biochemical parameters. Cluster validation analysis based on Dunn analysis for internal coherence and FOM analysis for external homogeneity was applied. The $K$ means analysis produced four clusters with particularly significant clinical profiles. Basal differences on the urine metabolomic profiles among clinical phenotypes were explored and validated by OSC-PLS-DA models. Multivariate analysis (OSC-PLS-DA) of ${ }^{1} \mathrm{H}-\mathrm{NMR}$ spectra revealed that the model comparing the "obese and diabetic cluster" (OD-c) against the "healthier cluster" (H-c) showed the best predictability and robustness in terms of explaining the pairwise differences between clusters. When considering these two clusters, two different groups of metabolites were observed after following an intervention with wine polyphenol intake (WPI, 733 Equivalents of Gallic Acid [GAE/day] per 28 days). Cluster differences between baseline and post-intervention values of 24h-urine NMR metabolomic data were analyzed by ANOVA. Those associated to a specific metabotype (OD-c), glucose as the significantly characteristic of the group (FDR correction, $p<0.01$,) and lactate, betaine and dimethylamine with a trend; and those associated to wine polyphenol intervention (OD-c_WPI and H-c_WPI), tartrate (FDR correction $\mathrm{p}<0.001)$, and mannitol, threonine methanol, fucose and 3-hydroxyphenylacetate in a trending profile. On the other hand, 4-HPA (metabolite derived from gut microbial metabolism after wine polyphenol intake) significantly increased (FDR correction, $p<0.05)$ for H-c_WPI compared to OD-c_WPI and basal periods (H-c_BAS and OD-c_BAS), exhibiting a metabotypic intervention effect. This study provides efficient strategies for targeting the heterogeneity in individual's responsiveness to dietary intervention and the identification of health benefits in specific population groups. 


\section{INTRODUCTION}

54 Metabolic phenotypes (metabotypes) are the result of interactions among several different factors (diet, lifestyle, gut microbiota, genetics, etc.), and describe characteristic metabolic profiles reflecting the biochemistry, the physiological status, and the environmental exposure in a population (Rezzi, Ramadan et al. 2007; Holmes, Wilson et al. 2008). Applications of metabolic phenotyping in nutrition research could be very useful in terms of assigning individuals to a particular metabolic phenotype. This could help improve our understanding of the linkage between both diet and disease with the different individual metabotypes (McNiven, German et al. 2011; Kinross, Li et al. 2014).

Metabolomic technologies permit the characterization of large numbers of small molecules in human biofluids. ${ }^{1} \mathrm{H}-\mathrm{NMR}$-based metabolomics is a very robust technique for performing metabolomic studies, enabling the simultaneous detection and quantification of a wide range of different metabolites. Because of this, NMR-based metabolomics has been applied in a variety of disciplines. In the field of nutrition, NMR-based metabolomics has been used to identify the most significant changes in a metabolic profile arising from dietary intervention studies, dietary biomarker studies and diet related disease studies (Brennan 2014). It can also be used to identify new small molecule candidates for disease biomarkers (Rupérez, Ramos-Mozo et al. 2012; Yang, Wang et al. 2013)

Cardiovascular disease (CVD) is the leading cause of mortality worldwide, with CVDassociated deaths rising very quickly in low-to-middle income countries. Modifiable risk factors for CVD—which include hypertension, smoking, abdominal obesity, abnormal lipids, diabetes mellitus, stress, low consumption of fruits and vegetables, and lack of regular physical activity—are the major contributors to CVD morbidity and mortality (Dahlöf 2010). Additionally, reduced plasma HDL levels and elevated plasma TAG concentrations are known to be significant risk factors for ischemic heart disease (IHD) (Lewington, Whitlock et al. 2007; Frikke-Schmidt, Nordestgaard et al. 2008). C-reactive protein (CRP) is another CVD risk marker (Ridker, Danielson et al. 2009). In addition, high plasma levels of homocysteine are 
considered to be a risk factor for vascular disease, heart failure and strokes (Kaptoge, Di Angelantonio et al. 2010). Another important risk factor is type 2 diabetes mellitus (T2D). The prevalence of T2D is increasing rapidly around the world. Clinical predictors such as body mass index (BMI), fat distribution measured by Waist-hip ratio (WHR), CRP and fasting blood glucose levels can be helpful in measuring diabetes risk (Pradhan, Manson et al. 2001; Wilson, Meigs et al. 2007; Wannamethee, Papacosta et al. 2010; Wang, Larson et al. 2011).

The low incidence of coronary heart disease (CHD) in Mediterranean countries has been partly assigned to their distinct dietary habits (Dauchet, Amouyel et al. 2009). Several studies have shown an inverse association between the Mediterranean diet and the incidence of CVD (Estruch, Ros et al. 2013). As one of the main constituents of Mediterranean diet, wine and its components, especially polyphenols, may provide additional health benefits (Chiva-Blanch, Urpi-Sarda et al. 2013). In particular, the regular consumption of wine polyphenols used in this study appears to mitigate CVD risk factors, leading to reduced blood pressure (Chiva-Blanch, Urpi-Sarda et al. 2012) and inflammatory parameters (Chiva-Blanch, Urpi-Sarda et al. 2012). The health benefits of polyphenols provided by wine intake are of particular interest. In the present study, a long-term feeding trial was performed to determine changes in urinary metabolites between different metabotypes. Therefore, the aim of the present work was to classify a specific population into phenotypic groups according to their biochemical characteristics, and then to use ${ }^{1} \mathrm{H}-\mathrm{NMR}$-based urinary metabolomics to observe the different metabolic responses after red wine polyphenols intake.

\section{MATERIAL AND METHODS}

\section{1 Subjects and Study Design}

The study was a prospective, randomized, crossover, and controlled trial (Chiva-Blanch, UrpiSarda et al. 2012). High-risk subjects aged $\geq 55$ years without documented CHD (CHD: ischemic heart disease — angina/recent or past myocardial infarction/previous or cerebral vascular accident, peripheral vascular disease) were recruited for the study. The subjects 
included had diabetes mellitus or more than three of the following CHD risk factors: tobacco smoking, hypertension, hypercholesterolemia, plasma LDL cholesterol $\geq 160 \mathrm{mg} / \mathrm{dL}$, plasma HDL cholesterol $<40 \mathrm{mg} / \mathrm{dL}$, obesity (BMI (in $\mathrm{kg} / \mathrm{m} 2$ ) $\geq 30$ ), and/or a family history of premature CHD (first-line male relatives $<55$ years or females $<65$ years). Participants had to voluntarily give signed informed consent. Subjects with a previous history of CVD, any severe chronic disease, alcoholism, or other toxic substance abuse were excluded.

To fulfil the objectives of the present study, we used ${ }^{1} \mathrm{H}-\mathrm{NMR}$ spectroscopy to evaluate the urinary metabolomes from 57 participants between baseline and after 28 days of red wine polyphenols intake (WPI, polyphenol content:733 Equivalents of Gallic Acid [EGA/day]) in form of dealcoholized wine from a Merlot grape variety. Results of polyphenol composition analysis of the beverages are shown in Supplemental material, Table S1. The Institutional Review Board of the hospital approved the study protocol, and all participants gave written consent before participation in the study. The trial has been registered in the Current Controlled Trials in London, International Standard Randomized Controlled Trial Number (ISRCTN88720134).

\subsection{Anthropometric Measurements and Biochemical Analyses}

Anthropometric measurements and biochemical analyses were performed using standardized methods (Estruch, Martínez-González et al. 2006). BMI and WHR were measured in all the participants to evaluate their obesity status. Systolic and diastolic blood pressures as well as heart rate were also measured. Clinical parameters were tested in the blood and urine of participants at the beginning of the study (baseline) in order to characterize the biochemical status of each participant. Blood glucose levels, total cholesterol, high-density lipoprotein cholesterol (HDL), low-density lipoprotein cholesterol (LDL), LDL/HDL ratio, triacylglycerides (TAG), 24h-diuresis, plasmatic creatine, uric acid, aminotransferases, bilirubin, ferritin, C-reactive protein, albumin, enzymes (alkaline phosphatase, lactate dehydrogenase), ions $\left(\mathrm{Na}^{+}, \mathrm{K}^{+}\right)$, as well as globulins, apolipoprotein levels, hemoglobin and red 
blood cell count; with several coagulation parameters (prothrombin, thrombin, fibrinogen) were measured. In total, 69 anthropometric and biochemical baseline parameters were evaluated. These are shown in Table 1.

\subsection{Biochemical Biomarkers and Clinical Phenotype by a $k$-means Algorithm}

The final data set contained 69 variables from 57 samples (of the initial set of 61 individuals, 4 were excluded because of incomplete data regarding clinical and anthropometric parameters). Prior to $k$-means analysis all variables were typified. All cluster metrics were computed with 1000 different random initializations of the $k$-means algorithm in order to avoid local minima. A maximum number of 100 iterations were allowed in the $k$-means calculations. All computations were carried out using the R package for Statistical Computing v. 2.14.1. This included the statistics package for the $k$-means algorithm and the clValid package for the cluster validation analysis. Dunn analysis for internal coherence and FOM analysis for external homogeneity were applied to the dataset employing Euclidean distances and a $k$-means clustering algorithm. Our results suggest that a cluster solution consisting of 4 centers or groups (4 clusters) showed the optimal properties of internal coherence and grouping stability (the detailed methodology and the validation procedure are in the supplemental material).

\section{4 Metabolomic NMR Spectroscopy}

\section{4. $1^{1} H$-NMR sample preparation, data acquisition and processing}

The protocols used for this work were based on previously published methodology (VázquezFresno, Llorach et al. 2012). The urine samples were thawed, vortexed, and centrifuged at 13,200 rpm for $5 \mathrm{~min}$. The supernatant $(600 \mu \mathrm{L})$ from each urine sample was mixed with an internal standard solution (120 $\mu \mathrm{L}$, consisting of $0.1 \%$ TSP (3-(trimethylsilyl)-proprionate2,2,3,3-d4, chemical shift reference), $2 \mathrm{mM}$ of sodium azide $\left(\mathrm{NaN}_{3}\right.$, bacteriostatic agent), and $1.5 \mathrm{M} \mathrm{KH}_{2} \mathrm{PO}_{4}$ in $99 \%$ deuterium water $\left.\left(\mathrm{D}_{2} \mathrm{O}\right)\right)$. The optimized $\mathrm{pH}$ of the buffer was set at 7.0, with a potassium deuteroxide (KOD) solution, to minimize variations in the chemical shifts of the NMR resonances. The mixture was transferred to a 5-mm NMR tube. The processed 
spectral data were bucketed in domains of $0.005 \mathrm{ppm}$ and integrated using ACD/NMR

Processor 12.0 software (Advanced Chemistry Development, Inc.). The spectral region between 4.75 and $5.00 \mathrm{ppm}$ was excluded from the data set to avoid spectral interference from residual water.

\subsection{Statistical Analysis}

\subsubsection{Biochemical biomarkers and phenotyping cluster differences}

Clusters were performed using $k$-means cluster analysis as described previously. A Kolmogorov-Smirnov test $(p<0.05)$ was used to test the normality of the all variables using SPSS, version 18.0 for Windows (SPSS ${ }^{\circledR}$, Chicago, IL, USA). ANOVA analysis was performed to evaluate differences in the mean biochemical measurements across clusters where statistical differences were analyzed $(p<0.05)$. Comparisons between clusters were assessed using a Tukey post-hoc multiple comparison test. In the case of non-parametric variables, a Kruskall Wallis test was used to test significant differences. Additionally, a Mann-Whitney test was used to detect significances between clusters. All these tests were performed by SPSS, version 18.0 for Windows (SPSS ${ }^{\circledR}$, Chicago, IL, USA).

\subsubsection{Metabolomic cluster analysis- OSC-PLS-DA multivariate analysis}

Data generated from the NMR spectral integration were submitted to MetaboAnalyst (Xia, Mandal et al. 2012). Data were normalized using the sum of the spectral intensities, then log transformed and Pareto scaled. Data were then analyzed using the SIMCA-P+ 13 software (Umetrics, Umea, Sweden) by multivariate discriminant analysis OSC-PLS-DA. A pairwise comparison analysis between the four clusters was carried out. The quality of the models was evaluated by the goodness-of-fit parameter $\left(\mathrm{R}^{2} \mathrm{X}\right)$, the proportion of the variance of the response variable that is explained by the model $\left(R^{2} Y\right)$ and the predictive ability parameter $(\mathrm{Q})$, which was calculated using seven-fold internal cross-validation (Vázquez-Fresno, Llorach et al. 2014). Validation of the OSC-PLS-DA models was carried out by a permutation test $(n=200)$. Additional information about the methodology is provided in the supplementary data. After 
untargeted analysis with baseline samples which characterized two most discriminant clusters, then, the quantification of the samples was performed for these two clusters.

\subsection{Metabolomic phenotype analysis by ANOVA}

Quantified data were submitted to MetaboAnalyst in order to find possible differences between clusters after WPI and normalized (24-h urine volume normalization, cube root transformed and Pareto scaled) (Xia, Mandal et al. 2012) before further analysis. Metabolites were analyzed by a one-way ANOVA test followed by Fisher's LSD test for multiple comparisons. The false discovery rate (FDR) test, a statistical approach to the problem of multiple comparisons, was used in this study to counter the effect of multiple testing and verify the most discriminating metabolites (Benjamini and Hochberg 1995). Box-plots were used to show the statistical differences between treatments with $P$ values $<0.05$ being considered significant. Figure 1 displays a summary of the steps followed in this study.

\subsection{Metabolite Identification and Quantification}

The methyl singlet produced by a known quantity of TSP $(0.97 \mathrm{mM})$ was used as an internal standard for chemical shift referencing (set to $0 \mathrm{ppm}$ ) and for quantification. The ${ }^{1} \mathrm{H}-\mathrm{NMR}$ spectra were analyzed using the Chenomx NMR Suite Professional Software package (version 7.8; Chenomx Inc, Edmonton, ALB, Canada), which permitted both identification and quantification by manually fitting the NMR spectra to an internal metabolite database.

\section{RESULTS AND DISCUSSION}

\section{1 Characterization of Clinical Phenotypes.}

61 participants were initially recruited into this study; of these, 57 participants were included in the final cluster analysis ( 4 were removed from the study because an incomplete biochemical profile). Of the 69 baseline biochemical parameters, $k$-means cluster analysis classified 4 
distinct phenotypic groups: cluster $1(n=12)$, cluster $2(n=13)$, cluster $3(n=14)$ and cluster 4 $(\mathrm{n}=18)$. Age, smoking habits, mean dietary intake, mean concentrations of biochemical parameters and statistical tests for each cluster are presented in Table 1. Cluster 1 was defined by a significantly lower systolic blood pressure $(\mathrm{mmHg}), \alpha 2$-globulin $(\%)$ and neutrophil levels (\%); higher total cholesterol (mg/dL), LDL cholesterol (mg/dL), apolipoprotein B (mg/dL), and apolipoprotein $\mathrm{B} /$ apolipoprotein $\mathrm{A}$ ratio (APOB/APOA), compared with all other clusters. Cluster 2 showed lower LDL/HDL ratio compared with all other clusters and significantly higher blood glucose levels compared to cluster 4. Cluster 3 was characterized by significantly higher BMI values, $\alpha 2$-globulin (\%), $\beta$-globulin (\%),albumin/globulin ratio, and homocysteine $(\mu \mathrm{mol} / \mathrm{L})$ levels and a lower albumin percentage $(\%)$ compared with the other clusters. In addition, CRP values were the highest in cluster 3 and statistically significant compared with clusters 1 and 4 . Furthermore, glucose levels were significantly higher in cluster $3(>126 \mathrm{mg} / \mathrm{dL})$ compared with cluster $4(<110 \mathrm{mg} / \mathrm{dL})$. More than $>126 \mathrm{mg} / \mathrm{dL}$ is diagnostic of T2D following the American Diabetes Association (ADA) criteria. Cluster 3 had the highest but not statistically significant values of the WHR index, a measure of fat distribution and also a BMI $>30$ indicating an obese participants cluster (Apovian and Gokce 2012). There is a strong positive association between obesity (measured by BMI) and risk of T2D in men (Wannamethee, Papacosta et al. 2010). In epidemiological studies, high plasma levels of homocysteine (hyperhomocysteinemia) are considered to be a risk factor for vascular disease (Welch and Loscalzo 1998), heart failure and strokes (Collaboration 2002). Among persons with T2D, the association between homocysteine levels and cardiovascular disease may be stronger than that in non-diabetic individuals (Ndrepepa, Kastrati et al. 2008). Moreover, cluster 3 showed the lowest HDLcholesterol levels and the highest TAG levels compared to the other clusters. These features are considered risk factors for IHD (Lewington, Whitlock et al. 2007; Frikke-Schmidt, Nordestgaard et al. 2008). Finally, cluster 4 showed significantly lower concentrations of TAG $(\mathrm{mg} / \mathrm{dL})$, leucocyte count $\left(\times 10^{9} / \mathrm{L}\right)$, neutrophils $\left(\times 10^{9} / \mathrm{L}\right)$, lymphocytes $\left(\times 10^{9} / \mathrm{L}\right)$ and erythrocyte sedimentation rate $(\mathrm{mm} / \mathrm{h})$ than cluster 3 ; also $\mathrm{K}(\mathrm{mEq} / \mathrm{L})$ presented lower levels compared to other clusters. The elevated circulating white blood cell count (neutrophils, lymphocytes and 
monocytes) has been proposed as one of a few biomarkers of potential utility for cardiovascular disease risk prediction (Horne, Anderson et al. 2005). Moreover, the erythrocyte sedimentation rate $(<10 \mathrm{~mm} / \mathrm{h})$ may be indicative of inflammation and a useful additional diagnostic criterion for coronary heart disease (Yayan 2012). On the other hand, low serum potassium levels $(<4$ $\mathrm{mEq} / \mathrm{L}$ ) in a propensity-matched study was associated with higher mortality and chronic heart failure (Ahmed, Zannad et al. 2007). Overall, cluster 4 had lower levels of cardiovascular disease biomarkers than all other clusters (Table 1).

\subsection{Clinical Phenotypes and NMR-based Metabolomic Profiles}

After separation of the participants into 4 biochemically distinct clusters, an OSC-PLS-DA analysis was performed to discriminate the clusters by their NMR-derived urinary profiles. The results obtained by OSC-PLS-DA showed that the most strongly discriminated clusters were cluster 3 versus cluster 4 (see Supplemental Material); for this reason, all subsequent analyses were focused on further characterizing cluster 3 which was named the "obese and diabetic cluster" (OD-c), versus cluster 4 or named the "healthier cluster" (H-c).

\section{3 Metabolomic Phenotype Analysis to Responses to Wine Polyphenol Intake}

Table 2 presents the results from the multiple comparison ANOVA analysis comparing cluster OD-c and H-c before and after wine polyphenols intake (WPI). Several metabolites exhibited to be associated to wine polyphenols intervention including tartrate, 4-hydroxyphenylacetate (4HPA), 3-hydroxyphenylacetate (3-HPA), mannitol, methanol threonine and fucose. Further, 4 metabolites presented an association to metabolic phenotype (OD-c) which includes glucose, lactate betaine and dimethylamine, associated to obesity and TD2 (Xie, Waters et al. 2012; Menni, Fauman et al. 2013).

After false discovery rate (FDR) correction, tartrate, glucose and 4-hydroxyphenylacetate (4HPA) exhibited significant results. Different patterns of response were observed for these 3 metabolites: Tartrate was higher for both clusters after WPI (OD-c_WPI and H-c_WPI) (wine polyphenols intervention metabolite). Glucose was higher in the baseline group and after 
intervention in cluster OD-c (OD-c_BAS, OD-c_WPI) compared with cluster H-c (H-c_BAS and H-c_WPI) (metabolic phenotype related metabolite) characteristic for cluster OD-c. Finally, 4-HPA showed higher urinary excretion after WPI among subjects H-c_WPI than those in ODc_WPI and at baseline (OD-c_BAS, H-c_BAS), exhibiting a distinct post-intervention metabolic response in individuals for different clusters (metabotypic intervention effect). Boxplots show the statistical differences observed for these metabolites by multiple comparison ANOVA analysis (Figure 2).

Tartrate is the major organic acid in grapes and so it is also present in wine (Son, Kim et al. 2008; Son, Hwang et al. 2009). Recently, it has been proposed to be a biomarker of wine consumption for both interventional and epidemiological studies (Vázquez-Fresno, Llorach et al. 2014). The tartrate urinary excreted amounts for OD-c_WPI were $1.06 \pm 0.19$ mmols $(84.57 \pm 14.58 \mu \mathrm{M} / \mathrm{mM}$ creatinine), as well as H-c_WPI $1.29 \pm 0.29 \mu$ mols $(107.89 \pm 16.69$ $\mu \mathrm{M} / \mathrm{mM}$ creatinine) in $24 \mathrm{~h}$-urine samples (Table 2). Similar to our results, a recent study reported a tartrate concentration of $91.8 \mu \mathrm{g} / \mathrm{mg}$ creatinine $(73.69 \mu \mathrm{M} / \mathrm{mM}$ creatinine) measured after 10h of acute wine intake (200 ml) (Regueiro, Vallverdú-Queralt et al. 2013). Additionally, the presence of this metabolite at statistically significant levels in both groups after WPI demonstrated a global compliance by all individuals in this intervention study.

The presence of glucose in urine has long been used as an indicator of diabetes mellitus (Urakami, Kubota et al. 2005). T2D is characterized by the presence of glucose in urine, obesity, high levels of homocysteine and CRP, which are all characteristics of cluster OD-c subjects (Table 1). Moreover, there is a strong positive association between obesity (measured by BMI) and T2D risk (Wannamethee, Papacosta et al. 2010). Glucose excretion amounts for volunteers corresponding to the OD-c were $14.04 \pm 7.56 \mathrm{mmols}(2157.79 \pm 1108.56 \mu \mathrm{M} / \mathrm{mM}$ creatinine) and $13.78 \pm 7.85 \mathrm{mmols}(1613.70 \pm 1042.12 \mu \mathrm{M} / \mathrm{mM}$ creatinine $)$ in $24 \mathrm{~h}$-urine samples for the OD-c_BAS and OD-c_WPI groups, respectively. These values were significantly higher than concentrations found in normal urine (12.5 - 58.4 $\mu \mathrm{M} / \mathrm{mM}$ creatinine) (Bouatra, Aziat et al. 
2013). When reported values of glucose in urine are $\geq 100 \mathrm{mg} / \mathrm{dl}(5.5 \mathrm{mM})$ it is considered to be a positive test for diabetes (Urakami, Kubota et al. 2005).

Lastly, 4-hydroxyphenylacetate (4-HPA) is a metabolite involved in tyrosine and phenylalanine metabolism. Also, 4-HPA is a compound that is known to be increased in urine after consumption of wine (Vázquez-Fresno, Llorach et al. 2012), chocolate (Martin, Rezzi et al. 2009), or cranberries (Prior, Rogers et al. 2010). This is because it is also a metabolic byproduct of polyphenol degradation by gut microbiota (Moco, Martin et al. 2012), particularly $F$. prausnitzii, Bifidobacterium, Clostridium difficile, Subdoligranulum, Lactobacillus sp. are described to be responsible of metabolism of 4-HPA (Nicholson, Holmes et al. 2012). The 4HPA excretion amount for the differential response cluster (H-c_WPI) was $0.28 \pm 0.03 \mathrm{mmols}$ $(25.35 \pm 1.48 \mu \mathrm{M} / \mathrm{mM}$ creatinine), significantly higher than excretion values described in the literature in normal conditions (1.4-14.6 $\mu \mathrm{M} / \mathrm{mM}$ creatinine) (Bouatra, Aziat et al. 2013). It has been described that obese and diabetic people experience changes in gut microbial metabolites as a result of these cardiovascular related pathologies (Shen, Obin et al. 2013). Some studies found a decrease of Bifidobacterium, F. prausnitzii, and some species of Clostridium and Lactobacillus in obese (Tagliabue and Elli 2013) and diabetic subjects (Everard and Cani 2013). These findings are in agreement with our results, as lower levels of 4-HPA were found in cluster OD-c than in cluster H-c after wine polyphehols intake.

\section{CONCLUSIONS}

The present study has shown that phenotypic analysis using an unsupervised clustering technique ( $k$-means analysis) can identify clusters according with their biochemical profiles. The two most discriminating clusters were named according to their clinical parameters and identified as the "obese and diabetic cluster" (OD-c) and the "healthier cluster" (H-c). Moreover, metabolomic phenotyping using NMR detected a distinct metabolic response between individuals grouped in these phenotypic clusters. In particular, comparisons between 
314 OD-c and H-c exhibited different levels of excretion of 4-HPA after wine polyphenols intake.

315 Likewise, a metabolite linked with a specific metabotype (glucose) and another metabolite

316 linked with dietary intervention (tartrate) were also observed. According to our results subjects

317 in OD-c could have altered the gut metabolism compared to individuals of H-c. Lastly, this

318 approach showed that clinical phenotyping combined with metabolomic analysis can produce

319 interesting quantitative results, providing new insights about the relationship between diet, gut

320 microbiota and health.

\section{ACKNOWLEDGEMENTS}

Supported by the Spanish National Grants from Ministry of Economy and Competitiveness

(MINECO, TEC2013-44666-R) and cofounded by FEDER (Fondo Europeo de Desarrollo

Regional): AGL2009-13906-C02-01, CIberOBN, as well as PI13/01172 Project, (Plan $N$ de I+D+i

2013-2016) by ISCII-Subdirección General de Evaluación y Fomento de la Investigación and the

JPI HDHL FOODBALL (PCIN-2014-133). We also thank the award of 2014SGR1566 from the

Generalitat de Catalunya's Agency AGAUR. R.V.-F, and R. Ll. would like to thank the FPI

fellowship and the "Ramon y Cajal" programmes of the Spanish Government and the Fondo Social

Europeo. CIBER-BBN is an initiative of the Spanish ISCIII. We thank the participants for their collaboration in the study.

The authors have declared no conflict of interest.

334 Abbreviations: WPI: wine polyphenols intake; BAS: baseline period; H-c: Healthier cluster;

335 OD-c: obese and diabetic cluster; CVD: cardiovascular disease; CHD: coronary heart disease;

336 T2D: type 2 Diabetes Mellitus; LDL: low density lipoprotein; HDL: high density lipoprotein;

337 BMI: body mass index; TAG: triacylglycerides; WHR: waist-to-hip index; OSC-PLS-DA: 
338 Orthogonal signal correction partial least-squares discriminant analysis; 4-HPA: 4-

339 hydroxyphenylacetate; FDR: false discovery rate 
Ahmed, A., F. Zannad, et al. (2007). "A propensity-matched study of the association of low serum potassium levels and mortality in chronic heart failure." Eur Heart J 28(11): 1334-1343.

Apovian, C. M. and N. Gokce (2012). "Obesity and cardiovascular disease." Circulation 125(9): 1178-1182.

Benjamini, Y. and Y. Hochberg (1995). "Controlling the False Discovery Rate: A Practical and Powerful Approach to Multiple Testing." Journal of the Royal Statistical Society. Series B (Methodological) 57(1): 289-300.

Bouatra, S., F. Aziat, et al. (2013). "The Human Urine Metabolome." PLoS ONE 8(9): e73076.

Brennan, L. (2014). "NMR-based metabolomics: From sample preparation to applications in nutrition research." Progress in Nuclear Magnetic Resonance Spectroscopy 83(0): 4249.

Chiva-Blanch, G., M. Urpi-Sarda, et al. (2012). "Differential effects of polyphenols and alcohol of red wine on the expression of adhesion molecules and inflammatory cytokines related to atherosclerosis: a randomized clinical trial." The American Journal of Clinical Nutrition 95(2): 326-334.

Chiva-Blanch, G., M. Urpi-Sarda, et al. (2012). "Dealcoholized Red Wine Decreases Systolic and Diastolic Blood Pressure and Increases Plasma Nitric Oxide: Short Communication." Circulation Research 111(8): 1065-1068.

Chiva-Blanch, G., M. Urpi-Sarda, et al. (2013). "Effects of red wine polyphenols and alcohol on glucose metabolism and the lipid profile: A randomized clinical trial." Clinical Nutrition 32(2): 200-206.

Collaboration, H. S. (2002). "Homocysteine and risk of ischemic heart disease and stroke: a meta-analysis." JAMA 288(16): 2015-2022.

Dahlöf, B. (2010). "Cardiovascular Disease Risk Factors: Epidemiology and Risk Assessment." The American Journal of Cardiology 105(1, Supplement): 3A-9A.

Dauchet, L., P. Amouyel, et al. (2009). "Fruits, vegetables and coronary heart disease." Nat Rev Cardiol 6(9): 599-608.

Estruch, R., M. A. Martínez-González, et al. (2006). "Effects of a Mediterranean-style diet on cardiovascular risk factors: a randomized trial." Ann Intern Med 145(1): 1-11.

Estruch, R., E. Ros, et al. (2013). "Primary Prevention of Cardiovascular Disease with a Mediterranean Diet." New England Journal of Medicine 368(14): 1279-1290.

Everard, A. and P. D. Cani (2013). "Diabetes, obesity and gut microbiota." Best practice \& research. Clinical gastroenterology 27(1): 73-83.

Frikke-Schmidt, R., B. G. Nordestgaard, et al. (2008). "Association of loss-of-function mutations in the ABCA1 gene with high-density lipoprotein cholesterol levels and risk of ischemic heart disease." JAMA 299(21): 2524-2532.

Frikke-Schmidt, R., B. G. Nordestgaard, et al. (2008). "Association of loss-of-function mutations in the ABCA1 gene with high-density lipoprotein cholesterol levels and risk of ischemic heart disease." JAMA 299(21): 2524-2532.

Holmes, E., I. D. Wilson, et al. (2008). "Metabolic phenotyping in health and disease." Cell 134(5): 714-717.

Horne, B. D., J. L. Anderson, et al. (2005). "Which white blood cell subtypes predict increased cardiovascular risk?" J Am Coll Cardiol 45(10): 1638-1643.

Kaptoge, S., E. Di Angelantonio, et al. (2010). "C-reactive protein concentration and risk of coronary heart disease, stroke, and mortality: an individual participant meta-analysis." Lancet 375(9709): 132-140. 
Kinross, J., J. V. Li, et al. (2014). "Nutritional modulation of the metabonome: applications of metabolic phenotyping in translational nutritional research." Current opinion in gastroenterology 30(2): 196-207.

Lewington, S., G. Whitlock, et al. (2007). "Blood cholesterol and vascular mortality by age, sex, and blood pressure: a meta-analysis of individual data from 61 prospective studies with 55,000 vascular deaths." Lancet 370(9602): 1829-1839.

Lewington, S., G. Whitlock, et al. (2007). "Blood cholesterol and vascular mortality by age, sex, and blood pressure: a meta-analysis of individual data from 61 prospective studies with 55,000 vascular deaths." Lancet 370(9602): 1829-1839.

Martin, F.-P. J., S. Rezzi, et al. (2009). "Metabolic Effects of Dark Chocolate Consumption on Energy, Gut Microbiota, and Stress-Related Metabolism in Free-Living Subjects." Journal of Proteome Research 8(12): 5568-5579.

McNiven, E. M. S., J. B. German, et al. (2011). "Analytical metabolomics: nutritional opportunities for personalized health." The Journal of Nutritional Biochemistry 22(11): 995-1002.

Menni, C., E. Fauman, et al. (2013). "Biomarkers for Type 2 Diabetes and Impaired Fasting Glucose Using a Nontargeted Metabolomics Approach." Diabetes 62(12): 4270-4276.

Moco, S., F.-P. J. Martin, et al. (2012). "Metabolomics View on Gut Microbiome Modulation by Polyphenol-rich Foods." Journal of Proteome Research 11(10): 4781-4790.

Ndrepepa, G., A. Kastrati, et al. (2008). "Circulating homocysteine levels in patients with type 2 diabetes mellitus." Nutr Metab Cardiovasc Dis 18(1): 66-73.

Nicholson, J. K., E. Holmes, et al. (2012). "Host-Gut Microbiota Metabolic Interactions." Science 336(6086): 1262-1267.

Pradhan, A. D., J. E. Manson, et al. (2001). "C-reactive protein, interleukin 6, and risk of developing type 2 diabetes mellitus." JAMA 286(3): 327-334.

Prior, R. L., T. R. Rogers, et al. (2010). "Urinary Excretion of Phenolic Acids in Rats Fed Cranberryt." Journal of Agricultural and Food Chemistry 58(7): 3940-3949.

Regueiro, J., A. Vallverdú-Queralt, et al. (2013). "Development of a LC-ESI-MS/MS Approach for the Rapid Quantification of Main Wine Organic Acids in Human Urine." Journal of Agricultural and Food Chemistry 61(27): 6763-6768.

Rezzi, S., Z. Ramadan, et al. (2007). "Human metabolic phenotypes link directly to specific dietary preferences in healthy individuals." J Proteome Res 6(11): 4469-4477.

Ridker, P. M., E. Danielson, et al. (2009). "Reduction in C-reactive protein and LDL cholesterol and cardiovascular event rates after initiation of rosuvastatin: a prospective study of the JUPITER trial." Lancet 373(9670): 1175-1182.

Rupérez, F., P. Ramos-Mozo, et al. (2012). "Metabolomic study of plasma of patients with abdominal aortic aneurysm." Analytical and Bioanalytical Chemistry 403(6): 16511660.

Shen, J., M. S. Obin, et al. (2013). "The gut microbiota, obesity and insulin resistance." Molecular Aspects of Medicine 34(1): 39-58.

Son, H. S., G. S. Hwang, et al. (2009). "Metabolomic studies on geographical grapes and their wines using $1 \mathrm{H}$ NMR analysis coupled with multivariate statistics." J Agric Food Chem 57(4): 1481-1490.

Son, H. S., K. M. Kim, et al. (2008). "1H nuclear magnetic resonance-based metabolomic characterization of wines by grape varieties and production areas." J Agric Food Chem 56(17): 8007-8016.

Tagliabue, A. and M. Elli (2013). "The role of gut microbiota in human obesity: Recent findings and future perspectives." Nutrition, Metabolism and Cardiovascular Diseases 23(3): 160-168.

Urakami, T., S. Kubota, et al. (2005). "Annual Incidence and Clinical Characteristics of Type 2 Diabetes in Children as Detected by Urine Glucose Screening in the Tokyo Metropolitan Area." Diabetes Care 28(8): 1876-1881. 
Vázquez-Fresno, R., R. Llorach, et al. (2012). "1H-NMR-based metabolomic analysis of the effect of moderate wine consumption on subjects with cardiovascular risk factors." ELECTROPHORESIS 33(15): 2345-2354.

Vázquez-Fresno, R., R. Llorach, et al. (2014). "An NMR metabolomics approach reveals a combined-biomarkers model in a wine interventional trial with validation in free-living individuals of the PREDIMED study." Metabolomics: 1-10.

Vázquez-Fresno, R., R. Llorach, et al. (2014). "Metabolomic Pattern Analysis after Mediterranean Diet Intervention in a Nondiabetic Population: A 1- and 3-Year Followup in the PREDIMED Study." Journal of Proteome Research.

Wang, T. J., M. G. Larson, et al. (2011). "Metabolite profiles and the risk of developing diabetes." Nat Med 17(4): 448-453.

Wannamethee, S. G., O. Papacosta, et al. (2010). "Assessing prediction of diabetes in older adults using different adiposity measures: a 7 year prospective study in 6,923 older men and women." Diabetologia 53(5): 890-898.

Welch, G. N. and J. Loscalzo (1998). "Homocysteine and atherothrombosis." $\underline{N \text { Engl J Med }}$ 338(15): 1042-1050.

Wilson, P. W., J. B. Meigs, et al. (2007). "Prediction of incident diabetes mellitus in middle-aged adults: the Framingham Offspring Study." Arch Intern Med 167(10): 1068-1074.

Xia, J., R. Mandal, et al. (2012). "MetaboAnalyst 2.0-a comprehensive server for metabolomic data analysis." Nucleic Acids Research 40(W1): W127-W133.

Xie, B., M. J. Waters, et al. (2012). "Investigating potential mechanisms of obesity by metabolomics." Journal of biomedicine \& biotechnology 2012: 805683.

Yang, Y., L. Wang, et al. (2013). "Study of metabonomic profiles of human esophageal carcinoma by use of high-resolution magic-angle spinning $1 \mathrm{H}$ NMR spectroscopy and multivariate data analysis." Analytical and Bioanalytical Chemistry 405(10): 3381-3389.

Yayan, J. (2012). "Erythrocyte sedimentation rate as a marker for coronary heart disease." Vasc Health Risk Manag 8: 219-223. 
472 Table 1. Biochemical and anthropometrical parameters of subjects and mean baseline

473 concentrations of individuals clusters. $P$-values of ANOVA test $\left({ }^{*}\right)$ for parametric variables and

474 Kruskall Wallis test $\left(^{\star}\right)$ for non-parametric variables, $(p<0.05)$ for both tests. Superscript

475 numbers $(1,2,3,4)$ indicate differences between number cluster shown, in Tukey post-hoc test (for

476 parametrical variables) and Mann-Whitney test.(for non-parametrical variables).

\begin{tabular}{|c|c|c|c|c|c|}
\hline & Cluster $1(n=12)$ & $\begin{array}{l}\text { Cluster } 2 \\
(n=13)\end{array}$ & Cluster $3(n=14)$ & Cluster $4(n=18)$ & $p$-value \\
\hline \multicolumn{6}{|l|}{ Characteristics } \\
\hline Age (y) & $59.83 \pm 8.62$ & $62.08 \pm 10.84$ & $61.21 \pm 5.98$ & $59.78 \pm 8.13$ & $0.87^{+}$ \\
\hline $\begin{array}{l}\text { Current smokers } \\
(\%)\end{array}$ & $1.75 \pm 0.45$ & $1.85 \pm 0.38$ & $1.86 \pm 0.36$ & $1.72 \pm 0.46$ & $0.14^{\star}$ \\
\hline \multicolumn{6}{|l|}{ Dietary Data } \\
\hline Energy (MJ) & $8074.70 \pm 211.65$ & $\begin{array}{l}8046.42 \pm 1738.6 \\
3\end{array}$ & $8347.50 \pm 1909.31$ & $7387.47 \pm 1838.73$ & $0.54^{+}$ \\
\hline TE protein $(\%)$ & $21.37 \pm 1.97$ & $20.55 \pm 3.17$ & $19.86 \pm 4.04$ & $21.12 \pm 3.94$ & $0.70^{+}$ \\
\hline $\begin{array}{l}\text { TE carbohydrates } \\
(\%)\end{array}$ & $43.19 \pm 7.02$ & $40.57 \pm 8.58$ & $43.05 \pm 8.27$ & $41.90 \pm 7.03$ & $0.83^{+}$ \\
\hline TE fat $(\%)$ & $33.68 \pm 6.60$ & $37.31 \pm 7.36$ & $36.44 \pm 6.26$ & $36.22 \pm 4.54$ & $0.56^{+}$ \\
\hline \multicolumn{6}{|c|}{ Anthropometrical and biochemical parameters } \\
\hline BMI $\left(\mathrm{kg} / \mathrm{m}^{2}\right)$ & $28.17 \pm 2.62$ & $27.33 \pm 2.78$ & $33.56 \pm 4.01^{1,2,4}$ & $29.02 \pm 3.86$ & $<0.001^{+}$ \\
\hline Waist-hip ratio & $0.94 \pm 0.05$ & $0.98 \pm 0.03$ & $0.99 \pm 0.05^{1}$ & $0.96 \pm 0.04$ & $0.01^{+}$ \\
\hline $\begin{array}{l}\text { Heart Rate } \\
\text { (beats/min) }\end{array}$ & $72.17 \pm 11.85$ & $69.69 \pm 7.09$ & $68.71 \pm 10.71$ & $68.78 \pm 8.94$ & $0.78^{+}$ \\
\hline $\begin{array}{l}\text { Systolic blood } \\
\text { pressure (mm Hg) }\end{array}$ & $124.58 \pm 15.08^{2,3,4}$ & $153.54 \pm 17.58$ & $143.14 \pm 13.79$ & $141.22 \pm 12.06$ & $<0.001^{+}$ \\
\hline $\begin{array}{l}\text { Diastolic blood } \\
\text { pressure (mm Hg) }\end{array}$ & $81.58 \pm 9.1$ & $79.23 \pm 7.36$ & $77.00 \pm 9.14$ & $84.50 \pm 8.59$ & $0.098^{+}$ \\
\hline CRP (mg/dL) & $0.15 \pm 0.09$ & $0.27 \pm 0.31$ & $0.37 \pm 0.29^{1,4}$ & $0.14 \pm 0.18^{2,3}$ & $0.028^{\star}$ \\
\hline Glucose (mg/dL) & $101.25 \pm 20.87$ & $119.92 \pm 28.62$ & $132.07 \pm 53.84^{1,4}$ & $95.22 \pm 18.10^{2,3}$ & $0.01^{\star}$ \\
\hline Diuresi 24h (mL) & $1587.50 \pm 621.35$ & $\begin{array}{l}1946.15 \\
\pm 753.45^{4}\end{array}$ & $1470.00 \pm 441.46$ & $1339.56 \pm 425.43$ & $0.03^{+}$ \\
\hline
\end{tabular}




\begin{tabular}{|c|c|c|c|c|c|}
\hline $\begin{array}{l}\text { Plasmatic } \\
\text { creatinine }(\mathrm{mg} / \mathrm{dL})\end{array}$ & $1.01 \pm 0.17$ & $0.96 \pm 0.19$ & $1.02 \pm 0.11$ & $0.96 \pm 0.11$ & $0.52^{+}$ \\
\hline Uric acid $(\mathbf{m g} / \mathbf{d L})$ & $6.58 \pm 1.47$ & $6.10 \pm 0.85$ & $6.89 \pm 1.38$ & $6.11 \pm 0.78$ & $0.19^{+}$ \\
\hline $\mathrm{Na}(\mathrm{mEq} / \mathrm{L})$ & $141.75 \pm 2.14$ & $141.15 \pm 1.77$ & $141.36 \pm 2.06$ & $140.72 \pm 1.49$ & $0.50^{+}$ \\
\hline$K(\mathbf{m E q} / \mathbf{L})$ & $4.28 \pm 0.23$ & $4.19 \pm 0.36$ & $4.24 \pm 0.33$ & $3.90 \pm 0.24^{1,2,3}$ & $0.002^{+}$ \\
\hline$P(\mathbf{m E q} / \mathbf{L})$ & $3.66 \pm 0.61^{2}$ & $3.02 \pm 0.49$ & $3.40 \pm 0.58$ & $3.09 \pm 0.67$ & $0.03^{+}$ \\
\hline $\operatorname{Mg}(\mathbf{m E q} / \mathbf{L})$ & $2.07 \pm 0.19$ & $2.21 \pm 0.31$ & $2.02 \pm 0.15$ & $2.12 \pm 0.16$ & $0.13^{+}$ \\
\hline $\mathrm{Fe}(\mathrm{mEq} / \mathrm{L})$ & $85.00 \pm 23.65$ & $99.38 \pm 26.96$ & $75.43 \pm 21.18$ & $94.89 \pm 30.19$ & $0.084^{+}$ \\
\hline $\begin{array}{l}\text { Total cholesterol } \\
(\mathrm{mg} / \mathrm{dL})\end{array}$ & $243.83 \pm 36.28^{2,3,4}$ & $189.69 \pm 14.68$ & $184.79 \pm 20.79$ & $203.28 \pm 40.97$ & $<0.001^{+}$ \\
\hline $\begin{array}{l}\text { LDL cholesterol } \\
(\mathrm{mg} / \mathrm{dL})\end{array}$ & $167.33 \pm 32.82^{2,3,4}$ & $116.92 \pm 14.14$ & $114.71 \pm 17.87$ & $137.67 \pm 33.57$ & $<0.001^{+}$ \\
\hline $\begin{array}{l}\text { HDL cholesterol } \\
(\mathrm{mg} / \mathrm{dL})\end{array}$ & $48.92 \pm 13.14$ & $52.46 \pm 9.98$ & $37.86 \pm 5.07^{1,2}$ & $46.61 \pm 10.09$ & $0.003^{+}$ \\
\hline $\begin{array}{l}\text { LDL } \\
\text { cholesterol:HDL } \\
\text { cholesterol ratio }\end{array}$ & $3.61 \pm 1.06$ & $2.31 \pm 0.54^{1,3,4}$ & $3.06 \pm 0.50$ & $2.98 \pm 0.53$ & $<0.001^{+}$ \\
\hline $\begin{array}{l}\text { Triglycerides } \\
(\mathrm{mg} / \mathrm{dL})\end{array}$ & $138.17 \pm 59.29$ & $101.69 \pm 33.27$ & $160.71 \pm 73.14^{2,4}$ & $95.61 \pm 35.28$ & $0.03^{+}$ \\
\hline $\begin{array}{l}\text { Apolipoprotein } \\
\text { APOA1 (mg/dL) }\end{array}$ & $146.58 \pm 23.36$ & $157.92 \pm 14.83^{3}$ & $138.43 \pm 15.16$ & $147.33 \pm 17.28$ & $0.05^{+}$ \\
\hline $\begin{array}{l}\text { Apolipoprotein } \\
\text { APOB }(\mathbf{m g} / \mathbf{d L})\end{array}$ & $136.42 \pm 24.98^{2,3,4}$ & $98.85 \pm 13.37$ & $103.36 \pm 13.89$ & $106.50 \pm 19.96$ & $<0.001^{+}$ \\
\hline APOB/A ratio & $0.95 \pm 0.23^{2,3,4}$ & $0.63 \pm 0.095$ & $0.76 \pm 0.15$ & $0.72 \pm 0.086$ & $<0.001^{+}$ \\
\hline ASAT (UI/L) & $30.08 \pm 13.56$ & $23.23 \pm 4.92$ & $28.14 \pm 10.6$ & $24.39 \pm 6.05$ & $0.203^{\star}$ \\
\hline ALAT (UI/L) & $44.42 \pm 41.39$ & $26.15 \pm 8.97$ & $31.21 \pm 16.33$ & $28.83 \pm 15.03$ & $0.230^{\star}$ \\
\hline GGT (UI/L) & $42.00 \pm 33.68$ & $26.08 \pm 7.95$ & $36.71 \pm 25.78$ & $27.22 \pm 17.36$ & $0.450^{\star}$ \\
\hline Bilirubin (mg/dL) & $0.77 \pm 0.31$ & $0.85 \pm 0.26^{3}$ & $0.56 \pm 0.12^{2}$ & $0.73 \pm 0.25$ & $0.024^{\star}$ \\
\hline $\begin{array}{l}\text { Alkaline } \\
\text { phosphatase (UI/L) }\end{array}$ & $135.00 \pm 20.69$ & $162.54 \pm 53.67$ & $127.29 \pm 31.30$ & $135.28 \pm 34.03$ & $0.082^{+}$ \\
\hline Lactate DH (UI/L) & $327.83 \pm 64.77$ & $305.31 \pm 16.25$ & $340.50 \pm 63.66$ & $357.39 \pm 46.26$ & $0.104^{+}$ \\
\hline Total proteins $(\mathrm{g} / \mathrm{L})$ & $74.08 \pm 2.64$ & $73.46 \pm 3.69$ & $72.14 \pm 2.69$ & $69.94 \pm 2.75^{1,2}$ & $0.001^{+}$ \\
\hline Albumin (g/L) & $47.33 \pm 1.92$ & $47.31 \pm 1.88^{3,4}$ & $44.00 \pm 2.77$ & $43.39 \pm 1.82$ & $<0.001^{+}$ \\
\hline Albumin (\%) & $65.87 \pm 2.11$ & $64.79 \pm 2.49$ & $60.32 \pm 3.82^{1,2,4}$ & $63.36 \pm 2.53$ & $<0.001^{+}$ \\
\hline
\end{tabular}




\begin{tabular}{|c|c|c|c|c|c|}
\hline$\alpha 1$ globulin (\%) & $2.76 \pm 0.22^{3,4}$ & $3.10 \pm 0.46$ & $3.53 \pm 0.48$ & $3.27 \pm 0.62$ & $0.002^{+}$ \\
\hline$\alpha 2$ globulin (\%) & $5.93 \pm 0.74^{2,3,4}$ & $7.39 \pm 1.14$ & $9.10 \pm 1.62^{1,2,4}$ & $7.25 \pm 1.49$ & $<0.001^{+}$ \\
\hline B globulin (\%) & $11.19 \pm 0.76$ & $11.21 \pm 1.28$ & $12.80 \pm 1.83^{1,2,4}$ & $11.02 \pm 0.87$ & $0.001^{+}$ \\
\hline$\Gamma$ globulin (\%) & $14.25 \pm 1.99$ & $13.52 \pm 2.04$ & $14.25 \pm 2.68$ & $15.10 \pm 1.77$ & $0.25^{+}$ \\
\hline $\begin{array}{l}\text { Albumin:globulin } \\
\text { ratio }\end{array}$ & $1.94 \pm 0.18$ & $1.85 \pm 0.21$ & $1.54 \pm 0.24^{1,2,4}$ & $1.74 \pm 0.19$ & $<0.001^{+}$ \\
\hline Ferritine(ng/mL) & $167.92 \pm 102.02$ & $\begin{array}{l}187.85 \pm \\
166.93\end{array}$ & $179.07 \pm 144.77$ & $208.56 \pm 152.61$ & $0.89^{+}$ \\
\hline $\begin{array}{l}\text { Folic acid (serum) } \\
(\mathrm{ng} / \mathrm{mL})\end{array}$ & $9.50 \pm 3.43$ & $10.98 \pm 2.79$ & $8.51 \pm 3.52$ & $10.27 \pm 4.65$ & $0.36^{+}$ \\
\hline $\begin{array}{l}\text { Intraerythrocytary } \\
\text { folic acid }(\mathrm{ng} / \mathrm{mL})\end{array}$ & $333.27 \pm 79.13$ & $401.54 \pm 69.95$ & $417.57 \pm 107.39$ & $374.38 \pm 80.27$ & $0.08^{+}$ \\
\hline $\begin{array}{l}\text { Vitamin B-12 } \\
(\mathrm{pg} / \mathrm{mL})\end{array}$ & $525.58 \pm 368.70$ & $\begin{array}{l}428.85 \pm \\
145.05\end{array}$ & $377.07 \pm 139.37$ & $380.44 \pm 110.63$ & $0.29^{\star}$ \\
\hline $\begin{array}{l}\text { Homocysteine } \\
(\mu \mathrm{mol} / \mathrm{L})\end{array}$ & $11.07 \pm 2.60$ & $11.17 \pm 1.24^{1,2,4}$ & $14.31 \pm 4.28$ & $11.26 \pm 1.79$ & $0.005^{+}$ \\
\hline $\begin{array}{l}\text { Hemoglobin } \\
\text { concentration }(\mathrm{g} / \mathrm{L})\end{array}$ & $152.75 \pm 9.92$ & $151.00 \pm 11.77$ & $143.57 \pm 9.15$ & $147.33 \pm 8.09$ & $0.08^{+}$ \\
\hline Hematocrit (L/L) & $0.45 \pm 0.03$ & $0.45 \pm 0.03$ & $0.43 \pm 0.03$ & $0.44 \pm 0.025$ & $0.16^{+}$ \\
\hline $\begin{array}{l}\text { Erythrocyte mean } \\
\text { corpuscular volume } \\
\text { (fL) }\end{array}$ & $89.80 \pm 2.59$ & $91.05 \pm 3.73$ & $90.35 \pm 5.30$ & $88.78 \pm 3.35$ & $0.42^{+}$ \\
\hline $\begin{array}{l}\text { Mean corpuscular } \\
\text { hemoglobin (pg) }\end{array}$ & $30.20 \pm 0.93$ & $30.82 \pm 0.98$ & $30.31 \pm 1.89$ & $29.88 \pm 1.16$ & $0.28^{+}$ \\
\hline $\begin{array}{l}\text { Mean corpuscular } \\
\text { hemoglobin } \\
\text { concentration }(\mathrm{g} / \mathrm{L})\end{array}$ & $336.25 \pm 5.15$ & $338.45 \pm 4.74$ & $335.57 \pm 7.44$ & $336.56 \pm 9.99$ & $0.78^{+}$ \\
\hline $\begin{array}{l}\text { Erytrocyte } \\
\text { sedimentation rate } \\
(\mathrm{mm} / \mathrm{h})\end{array}$ & $7.08 \pm 4.44$ & $8.08 \pm 3.86$ & $11.07 \pm 5.26^{1,4}$ & $5.44 \pm 2.31^{2,3}$ & $0.003^{\star}$ \\
\hline $\begin{array}{l}\text { Reed distribution } \\
\text { width }(\%)\end{array}$ & $13.06 \pm 0.58^{4}$ & $13.17 \pm 0.59$ & $13.59 \pm 0.66$ & $13.68 \pm 0.53$ & $0.01^{+}$ \\
\hline $\begin{array}{l}\text { Hemoglobin } \\
\text { distribution width } \\
(\mathrm{g} / \mathrm{L})\end{array}$ & $25.74 \pm 1.46$ & $24.49 \pm 1.96$ & $25.51 \pm 2.65$ & $26.03 \pm 2.18$ & $0.24^{+}$ \\
\hline $\begin{array}{l}\text { Platelet count } \\
(\times 109 / L)\end{array}$ & $282.17 \pm 56.36^{4}$ & $233.54 \pm 45.98$ & $264.64 \pm 63.99$ & $220.17 \pm 33.78$ & $0.006^{+}$ \\
\hline
\end{tabular}




\begin{tabular}{|c|c|c|c|c|c|}
\hline $\begin{array}{l}\text { Mean platelet } \\
\text { volume (fL) }\end{array}$ & $8.27 \pm 0.47$ & $9.11 \pm 0.74$ & $8.85 \pm 0.72$ & $8.89 \pm 0.99$ & $0.05^{+}$ \\
\hline $\begin{array}{l}\text { Leucocyte count } \\
\left(\times 10^{9} / \mathrm{L}\right)\end{array}$ & $6.84 \pm 1.73$ & $7.09 \pm 0.88$ & $7.96 \pm 1.23^{4}$ & $6.15 \pm 1.30$ & $0.004^{+}$ \\
\hline Neutrophils (\%) & $50.45 \pm 5.82^{2,3,4}$ & $63.84 \pm 8.78$ & $58.26 \pm 4.43$ & $58.21 \pm 6.32$ & $<0.001^{+}$ \\
\hline Lymphocytes (\%) & $35.83 \pm 4.42^{2,4}$ & $24.90 \pm 7.07$ & $29.90 \pm 5.06$ & $29.83 \pm 5.87$ & $<0.001^{+}$ \\
\hline Monocytes (\%) & $6.58 \pm 1.07$ & $5.85 \pm 1.09$ & $6.44 \pm 0.88$ & $7.47 \pm 0.63^{2,3}$ & $<0.001^{+}$ \\
\hline Eosinophils (\%) & $4.12 \pm 2.04^{2,4}$ & $2.65 \pm 1.23$ & $2.77 \pm 1.19$ & $2.15 \pm 0.72$ & $0.002^{+}$ \\
\hline Basophils (\%) & $0.71 \pm 0.25$ & $0.79 \pm 0.39^{4}$ & $0.57 \pm 0.2$ & $0.49 \pm 0.19$ & $0.01^{+}$ \\
\hline $\begin{array}{l}\text { Unclassified cells } \\
(\%)\end{array}$ & $2.16 \pm 0.95$ & $1.99 \pm 0.93$ & $2.05 \pm 0.50$ & $1.86 \pm 0.56$ & $0.726^{+}$ \\
\hline $\begin{array}{l}\text { Neutrophils ( } \\
\left.\times 10^{9} / \mathrm{L}\right)\end{array}$ & $3.49 \pm 1.11$ & $4.55 \pm 0.89^{1,4}$ & $4.63 \pm 0.79^{1,4}$ & $3.56 \pm 0.84$ & $0.001^{+}$ \\
\hline $\begin{array}{l}\text { Lymphocytes ( } \\
\left.\times 10^{9} / \mathrm{L}\right)\end{array}$ & $2.43 \pm 0.61^{2,4}$ & $1.75 \pm 0.46^{1,3}$ & $2.39 \pm 0.56^{2,4}$ & $1.85 \pm 0.57$ & $0.002^{+}$ \\
\hline Monocytes $\left(\mathrm{x}^{10}{ }^{9} / \mathrm{L}\right)$ & $0.45 \pm 0.12$ & $0.42 \pm 0.10$ & $0.52 \pm 0.13$ & $0.45 \pm 0.10$ & $0.24^{\star}$ \\
\hline Eosinophil $\left(\times 10^{9} / L\right)$ & $0.27 \pm 0.15$ & $0.19 \pm 0.086$ & $0.21 \pm 0.09$ & $0.13 \pm 0.05^{1,2,3}$ & $0.001^{\star}$ \\
\hline Basophils ( $\left.\times 10^{9} / \mathrm{L}\right)$ & $0.05 \pm 0.03$ & $0.05 \pm 0.04$ & $0.03 \pm 0.04$ & $0.08 \pm 0.01^{1,2}$ & $0.002^{\star}$ \\
\hline $\begin{array}{l}\text { Unclassified cells ( } \\
\left.\times 10^{9} / \mathrm{L}\right)\end{array}$ & $0.16 \pm 0.06$ & $0.15 \pm 0.06$ & $0.17 \pm 0.05^{4}$ & $0.11 \pm 0.05^{1,3}$ & $0.029^{\star}$ \\
\hline $\begin{array}{l}\text { Prothrombin time } \\
\text { (\%) }\end{array}$ & $97.58 \pm 3.68^{4}$ & $95.54 \pm 5.72$ & $96.00 \pm 4.93$ & $92.50 \pm 5.83$ & $0.126^{\star}$ \\
\hline $\begin{array}{l}\text { Prothrombin time } \\
\text { (seg) }\end{array}$ & $13.07 \pm 0.45$ & $13.23 \pm 0.78$ & $13.29 \pm 0.47$ & $13.56 \pm 0.67$ & $0.186^{+}$ \\
\hline $\begin{array}{l}\text { Thromboplastin } \\
\text { partial time (seg) }\end{array}$ & $28.48 \pm 0.89$ & $26.65 \pm 7.97$ & $26.38 \pm 7.55$ & $29.35 \pm 2.11$ & $0.386^{+}$ \\
\hline Fibrinogen $(g / L)$ & $3.18 \pm 0.51$ & $4.08 \pm 0.82^{1,4}$ & $3.73 \pm 0.62$ & $3.18 \pm 0.37$ & $<0.001^{+}$ \\
\hline
\end{tabular}

All values are mean $\pm \mathrm{SD}, p$-values are based on simple ANOVA test $\left(^{+}\right)$for parametric variables and

478 Kruskall Wallis test $\left.{ }^{\star}\right)$ for non-parametric variables, $(p<0.05$ for both tests); Superscript numbers

479 adjacent to values from each cluster denote a significant difference between indicated cluster number based on Tukey post-hoc test (for parametrical variables) and Mann-Whitney test.(for non-parametrical variables). TE protein \%: protein as percentage of total energy intake; TE carbohydrate \%: carbohydrate as percentage of total energy intake; TE fat \%: fat as percentage of total energy intake. PCR: c-reactive protein; BMI: body mass index; ASAT: aspartate aminotranspherase; ALAT: alanine aminotransferase; GGT:gamma-glutamyl transpeptidase; Na: sodium; K: potassium; P: phosphorous; Mg: Magnessium; Fe: 
487 Table 2. Urinary excretion amounts [mmols, 24h-urine] of metabolites after ANOVA analysis, in parenthesis $\mu \mathrm{M} / \mathrm{mM}$ creatinine. OD-c_BAS: obese and 488 diabetic cluster in basal period; H-c_BAS: healthier cluster in basal period; OD-c_WPI: obese and diabetic cluster after wine polyphenols intake; H-c_WPI:

489 healthier cluster after wine polyphenol intake. WPI: wine polyphenols intake; MTP: metabotype.4-HPA: 4-hydroxyphenylacetate; 3-HPA: 3-

490 hydroxyphenylacetate. DMA: dimethylamine. 
MEAN \pm SEM; mmols, 24h

$(\mu \mathrm{M} / \mathrm{mM}$ creatinine $)$

\begin{tabular}{|c|c|c|c|c|c|c|c|}
\hline Metabolite & OD-c_BAS & H-c_BAS & OD-c_WPI & H-c_WPI & $p$-value & $\begin{array}{c}\text { FDR } \\
\text { p-value }\end{array}$ & $\begin{array}{l}\text { Metabolite } \\
\text { information }\end{array}$ \\
\hline Tartrate & $\begin{array}{l}0.140 \pm 0.052 \\
(14.16 \pm 5.78)\end{array}$ & $\begin{array}{c}0.451 \pm 0.019 \\
(39.83 \pm 14.74)\end{array}$ & $\begin{array}{c}1.065 \pm 0.19 \\
(84.57 \pm 14.58)\end{array}$ & $\begin{array}{c}1.292 \pm 0.285 \\
(107.89 \pm 16.69)\end{array}$ & $7.09 \mathrm{E}-07$ & $6.02 \mathrm{E}-05$ & WPI \\
\hline Glucose & $\begin{array}{c}14.044 \pm 7.562 \\
(2157.79 \pm 1108.56)\end{array}$ & $\begin{array}{l}0.210 \pm 0.019 \\
(19.95 \pm 1.61)\end{array}$ & $\begin{array}{c}13.786 \pm 7.850 \\
(1613.70 \pm 1042.12)\end{array}$ & $\begin{array}{c}0.188 \pm 0.038 \\
(16.53 \pm 2.08)\end{array}$ & 0.0001 & 0.005 & МTP \\
\hline 4-HPA & $\begin{array}{l}0.170 \pm 0.025 \\
(17.23 \pm 2.04)\end{array}$ & $\begin{array}{l}0.163 \pm 0.013 \\
(15.52 \pm 1.13)\end{array}$ & $\begin{array}{l}0.184 \pm 0.022 \\
(16.23 \pm 1.95)\end{array}$ & $\begin{array}{l}0.280 \pm 0.029 \\
(25.35 \pm 1.48)\end{array}$ & 0.0008 & 0.02 & WPI-MTP \\
\hline 3-HPA & $\begin{array}{c}0.056 \pm 0.01 \\
(40.71 \pm 8.34)\end{array}$ & $\begin{array}{l}0.062 \pm 0.005 \\
(48.39 \pm 3.99)\end{array}$ & $\begin{array}{l}0.0856 \pm 0.016 \\
(56.04 \pm 10.97)\end{array}$ & $\begin{array}{l}0.101 \pm 0.012 \\
(75.7 \pm 10.43)\end{array}$ & 0.01 & 0.18 & WPI \\
\hline Mannitol & $\begin{array}{c}0.556 \pm 0.112 \\
(462.62+142.13)\end{array}$ & $\begin{array}{c}0.782 \pm 0.144 \\
(646.87 \pm 132.08)\end{array}$ & $\begin{array}{c}1.223 \pm 0.157 \\
(804.66 \pm 117.30)\end{array}$ & $\begin{array}{c}1.312 \pm 0.255 \\
(957.04 \pm 210.15)\end{array}$ & 0.005 & 0.99 & WPI \\
\hline Threonine & $\begin{array}{c}0.094 \pm 0.014 \\
(9.07 \pm 1.17)\end{array}$ & $\begin{array}{c}0.107 \pm 0.013 \\
(10.33 \pm 1.51)\end{array}$ & $\begin{array}{l}0.141 \pm 0.013 \\
(12.64 \pm 2.19)\end{array}$ & $\begin{array}{l}0.173 \pm 0.032 \\
(15.00 \pm 1.99)\end{array}$ & 0.02 & 0.18 & WPI \\
\hline Methanol & $\begin{array}{l}0.473 \pm 0.077 \\
(46.83 \pm 6.80)\end{array}$ & $\begin{array}{l}0.436 \pm 0.050 \\
(39.99 \pm 3.72)\end{array}$ & $\begin{array}{l}0.682 \pm 0.133 \\
(51.02 \pm 5.07)\end{array}$ & $\begin{array}{l}0.676 \pm 0.076 \\
(59.91 \pm 3.82)\end{array}$ & 0.03 & 0.30 & WPI \\
\hline Fucose & $\begin{array}{c}0.32 \pm 0.04 \\
(30.58 \pm 2.36)\end{array}$ & $\begin{array}{l}0.327 \pm 0.023 \\
(30.55 \pm 1.81)\end{array}$ & $\begin{array}{l}0.503 \pm 0.069 \\
(39.01 \pm 4.56)\end{array}$ & $\begin{array}{l}0.495 \pm 0.081 \\
(42.84 \pm 3.87)\end{array}$ & 0.04 & 0.31 & WPI \\
\hline Lactate & $\begin{array}{c}0.516 \pm 0.19 \\
(65.56 \pm 34.17)\end{array}$ & $\begin{array}{l}0.212 \pm 0.075 \\
(19.77 \pm 1.37)\end{array}$ & $\begin{array}{c}0.432 \pm 0.087 \\
(37.83 \pm 11.02)\end{array}$ & $\begin{array}{l}0.294 \pm 0.030 \\
(26.09 \pm 1.80)\end{array}$ & 0.04 & 0.33 & MTP \\
\hline Betaine & $\begin{array}{c}0.549 \pm 0.217 \\
(56.01 \pm 21.61)\end{array}$ & $\begin{array}{l}0.207 \pm 0.030 \\
(19.36 \pm 2.64)\end{array}$ & $\begin{array}{c}0.676 \pm 0.245 \\
(53.77 \pm 18.74)\end{array}$ & $\begin{array}{l}0.214 \pm 0.037 \\
(18.83 \pm 2.28)\end{array}$ & 0.02 & 0.18 & MTP \\
\hline DMA & $\begin{array}{l}0.469 \pm 0.021 \\
(51.68 \pm 7.82)\end{array}$ & $\begin{array}{l}0.503 \pm 0.048 \\
(45.89 \pm 3.20)\end{array}$ & $\begin{array}{l}0.905 \pm 0.230 \\
(65.36 \pm 8.11)\end{array}$ & $\begin{array}{l}0.568 \pm 0.078 \\
(51.21 \pm 4.62)\end{array}$ & 0.02 & 0.18 & MTP \\
\hline
\end{tabular}

492 


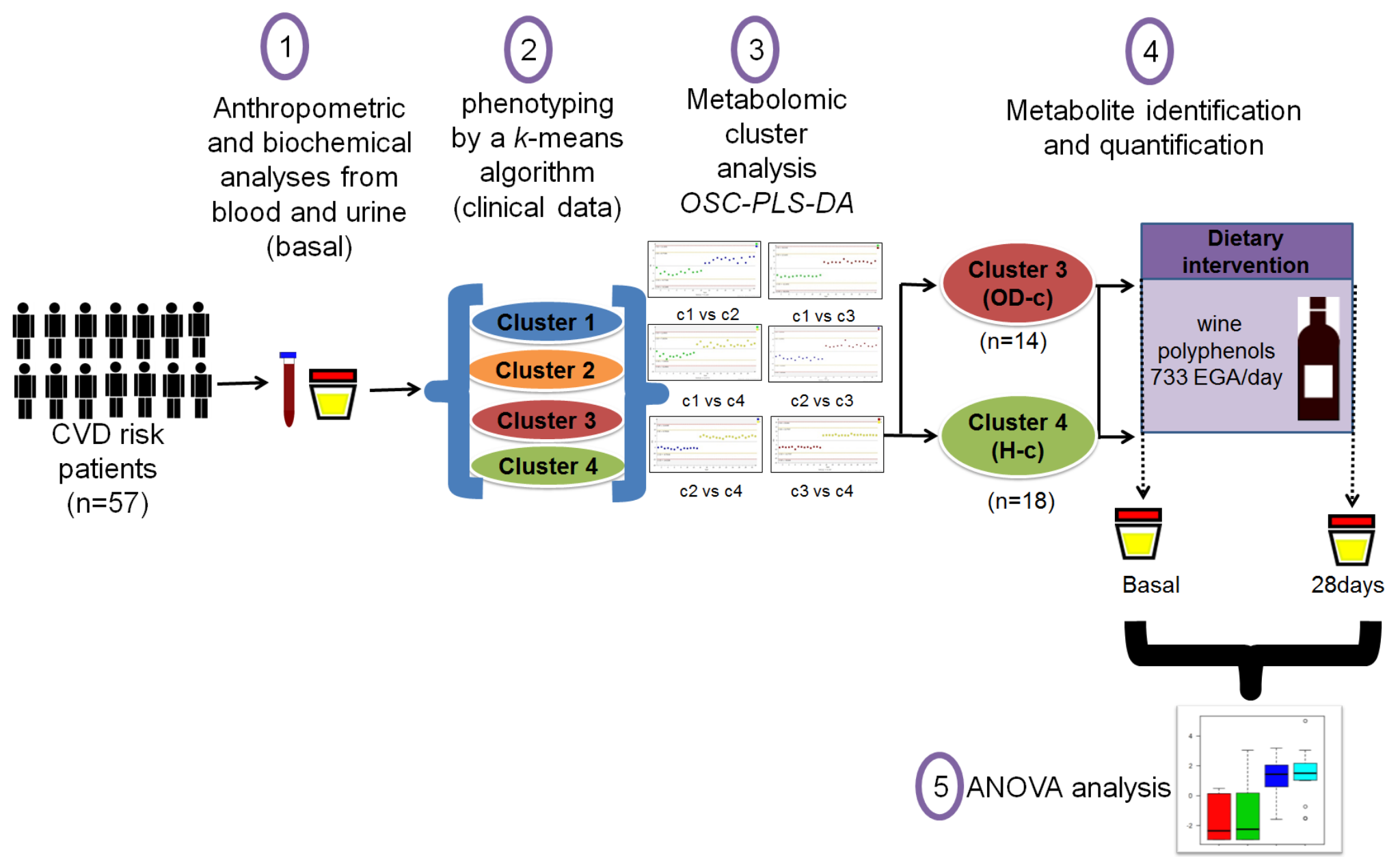




\section{Metabotype}

Glucose

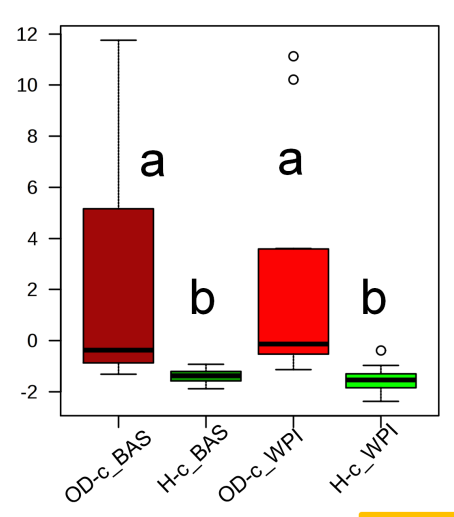

Wine polyphenols intervention

Tartrate

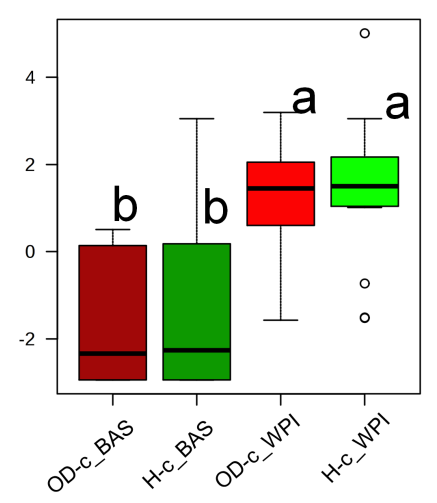

\section{Intervention effect}

on metabotype

4-hydroxyphenylacetate

497

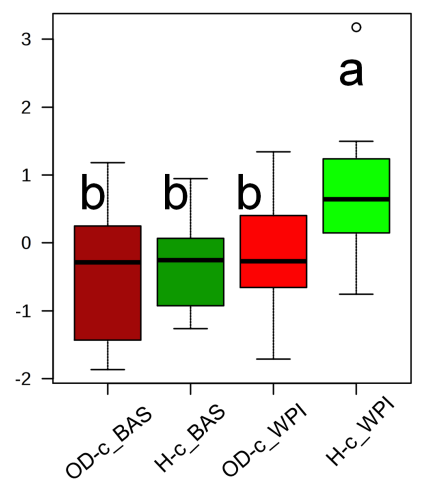

498 Figure 2. Box-plots of the metabolites derived from ANOVA test $(p<0.05$ after FDR

499 correction). Different letters indicate significant differences between interventions. OD-c_BAS:

500 obese and diabetic cluster in basal period; H-c_BAS: healthier cluster in basal period; OD-

501 c_WPI: obese and diabetic cluster after wine polyphenols intake; H-c_WPI: healthier cluster 502 after wine polyphenols intake. 